\title{
Optimized and Validated RP-HPLC Method for the Determination of Clopidogrel in Bulk and Pharmaceutical Formulation
}

\author{
R. Akter ${ }^{1}$, S. Banik*1 ${ }^{1}$ A. Ghosh ${ }^{2}$, M. M. O. Rashid ${ }^{1}$ \\ ${ }^{1}$ Department of Pharmacy, Noakhali Science and Technology University, Sonapur, Noakhali-3814, \\ Bangladesh \\ ${ }^{2}$ Department of Quality Assurance, NIPRO JMI Pharma Ltd., Shantibag, Dhaka-1217, Bangladesh
}

Received 3 June 2016, accepted in final revised form 15 July 2016

\begin{abstract}
This study was undertaken to develop a novel, simple, rapid, accurate and precise sensitive reverse phase HPLC method for estimating Clopidogrel in bulk and pharmaceutical dosage form. The current method in this study was achieved by Thermo Hypersil RP C-18 column $(100 \mathrm{~mm} \times 4.6 \mathrm{~mm}, 3.5 \mu \mathrm{m})$ using a mobile phase of Phosphate Buffer: Acetonitrile (pH 3.0) is 70: 30 at a column temperature of $25^{\circ} \mathrm{C}$. The effluent was monitored by UV detector at $238 \mathrm{~nm}$. The retention time of Clopidogrel was $4.75 \mathrm{~min}$ with a flow rate $1.0 \mathrm{~mL} / \mathrm{min}$. Calibration curve was linear in the range of $10-60 \mu \mathrm{g} / \mathrm{mL}$. The method was validated for linearity, precision, robustness and accuracy as per ICH guidelines. The results of all the validation parameters were well within their acceptance values (\%RSD $<2.0$ specified by the USP, ICH and FDA), which prove applicability of the proposed method for routine analyses and quality-control assay of Clopidogrel in pharmaceutical preparations.
\end{abstract}

Keywords: Clopidogrel; RP- HPLC; Accuracy; Precision.

(C) 2016 JSR Publications. ISSN: 2070-0237 (Print); 2070-0245 (Online). All rights reserved. doi: http://dx.doi.org/10.3329/jsr.v8i3.28032 J. Sci. Res. 8 (3), 439-446 (2016)

\section{Introduction}

Clopidogrel is a thienopyridine class of antiplatelet agent, mainly used to prevent blood clots in coronary artery disease, peripheral vascular disease, and cerebrovascular disease. It acts by inhibiting adenosine diphosphate (ADP) induced platelet aggregation and direct inhibition of ADP binding to its receptor and of subsequent ADP-mediated activation of the glycoprotein GPIIb/IIIa complex [1]. Clopidogrel was officially listed in the United States of Pharmacopeia (USP) in 2007. Chemically, it is designated as (+)- $\alpha-(2-$ chlorophenyl)-6,7-dihydrothieno[3,2-c]pyridine-5(4H)-acetic acid methyl ester sulfate

\footnotetext{
* Corresponding author: pharmasujan@yahoo.com
} 
with the molecular formula of $\mathrm{C}_{16} \mathrm{H}_{16} \mathrm{ClNO}_{2} \mathrm{~S}$ (Fig. 1) [2]. It is available in the market as tablets dosage form.

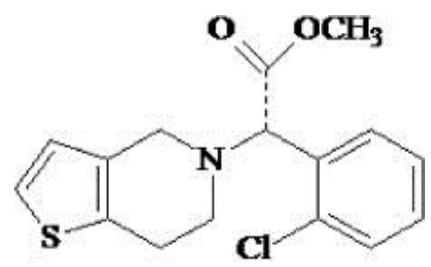

Fig.1. Chemical structure of Clopidogrel.

A detailed literature survey revealed that there is no official method available for the determination of Clopidogrel in pharmaceutical dosage forms but various assays for determining Clopidogrel in pharmaceutical dosage forms, including chemometry [3], spectrophotometry [4], thin-layer chromatography (TLC) [5], high-performance thin-layer chromatography (HPTLC) [6], high-performance liquid chromatography (HPLC) [710], mass spectrometry [11], and voltammetry [12]. However, in this study the aim has been designed to develop a new more accurate, simple, precise, reproducible, sensitive reverse phase HPLC method for the determination of Clopidogrel in bulk and tablet dosage forms. This method has been optimized and validated as per as the ICH guidelines.

\section{Materials and Methods}

\subsection{Materials}

Clopidogrel was obtained as a generous sample from Eskayef Bangladesh Limited. HPLC grade acetonitrile was procured from the Active Fine Chemicals Ltd., Bangladesh. Water for Injection (WFI) was obtained as a gift from Globe Pharmaceutical Ltd., Bangladesh. All chemicals and reagents used were of analytical grade in the present study. Anclog (Brand name), commercially available Clopidogrel tablet manufactured by Square Pharmaceutical Ltd. was purchased from our local market.

\subsection{Instrumentations}

The analysis of drugs was carried out on HPLC system (Shimadzu, Japan) on a C18 column with a UV-visible detector. A $20 \mu \mathrm{L}$ syringe was used for injecting the samples. A double-beam Shimadzu UV-1800 visible spectrophotometer was used for spectral studies. Degassing of the mobile phase was done by using an ultrasonic bath sonicator. An Axis balance was used for weighing the materials. 


\subsection{Chromatographic conditions}

The mobile phase consisting of sodium dihydrogen phosphate buffer ( $\mathrm{pH}$ 3.0) and acetonitrile in the ratio $70: 30 \mathrm{v} / \mathrm{v}$ was filtered through $0.45 \mu \mathrm{m}$ membrane filter before use, degassed and pumped from the solvent reservoir into the column at a flow rate of 1.0 $\mathrm{mL} / \mathrm{min}$. The detection was monitored at $238 \mathrm{~nm}$, and the run time was $4.75 \mathrm{~min}$. The volume of the injection loop was $10 \mu \mathrm{L}$ and prior to the injection of the drug solution. The column and the HPLC system were kept at $25^{\circ} \mathrm{C}$.

\subsection{Preparation of standard solution}

About $25 \mathrm{mg}$ of Clopidogrel was accurately weighed and transferred into a $50 \mathrm{~mL}$ volumetric flask. Then the reagent methanol was added to make up the volume up to the mark and the mixture was sonicated for $10 \mathrm{~min}$. After filtration $2 \mathrm{~mL}$ of this solution was taken into another clean and dry $50 \mathrm{~mL}$ volumetric flask and then diluted up to the mark using methanol.

\subsection{Preparation of sample solution}

Ten tablets were weight accurately and powdered. A quantity of tablet powder equivalent to $25 \mathrm{mg}$ of Clopidogrel was accurately weighed and transferred to a clean and dry $50 \mathrm{~mL}$ volumetric flask. After this the methanol was added to make up the volume up to the mark and then the mixture was sonicated for $10 \mathrm{~min}$. The solution was filtered through Whatman No. 42 filter paper. After filtration $2 \mathrm{~mL}$ of this solution was taken into another clean and dry $50 \mathrm{~mL}$ volumetric flask and diluted up to the mark with methanol.

\subsection{Method validation}

The proposed method was validated for linearity, limit of detection, limit of quantification, precision, and accuracy as per International Conference on Harmonization (ICH) guidelines [13,14].

\subsection{Linearity}

The linearity of an analytical procedure is its ability of producing results that are directly proportional to the concentrations of an analyte in the samples. The determination was repeated three times at each concentration $(10-60 \mu \mathrm{g} / \mathrm{mL})$ level. The linearity was evaluated by linear regression analysis, which was calculated by the least square regression method. 


\subsection{Limit of detection (LOD)}

Limit of detection (LOD) is defined as the lowest concentration of analyte that gives a detectable response. LOD was determined by the analysis of samples with known concentration of analyte and by establishing the minimum level at which the analyte can be reliably detected. LOD was calculated using the following equation [15].

$\mathrm{LOD}=3.3 \times \mathrm{S}_{\mathrm{o}} / \mathrm{b}$, where $S_{\mathrm{o}}$ and $b$ are the standard deviation of the response and the slope of the calibration curve.

\subsection{Limit of quantification (LOQ)}

Limit of quantification (LOQ) is defined as the lowest concentration that can be quantified reliably with a specified level of accuracy and precision. LOQ was determined by the analysis of samples with known concentrations of analyte and by establishing the minimum level at which the analyte could be quantified with acceptable accuracy and precision. LOQ was calculated using the following equations [15].

LOQ $=10 \times \mathrm{S}_{\mathrm{o}} / \mathrm{b}$, where $S_{\mathrm{o}}$ and $b$ are the standard deviation of the response and the slope of the calibration curve.

\subsection{Precision}

Precision was done by repeatability or intra-assay precision and intermediate precision. Repeatability studies were performed by analysis of concentration of $20 \mu \mathrm{g} / \mathrm{mL}$ six times on the same day. Intermediate precision was determined by repeating the same procedure by another analyst working in the laboratory.

\subsection{Accuracy}

The accuracy of the developed method was evaluated by determination of recovery at three different concentrations, equivalent to $80 \%, 100 \%$, and $120 \%$ of the amount in the pre-analysed dosage form as ICH guidelines and average recoveries were calculated. Triplicated injections were made for each concentration.

\subsection{Robustness}

To determine the robustness of the developed method, experimental conditions were purposely altered. The flow rate of the mobile was $1 \mathrm{~mL} / \mathrm{min}$. To study the effect of flow rate on the resolution, it was changed by $0.8 \mathrm{~mL} / \mathrm{min}$. The effect of the column temperature on resolution was studied at $30^{\circ} \mathrm{C}$ instead of $25^{\circ} \mathrm{C}$. 


\section{Results and Discussion}

To develop a suitable and robust HPLC method for the determination of Clopidogrel, different mobile phases were employed in this study to achieve the best separation and resolution. Finally, the final mobile phase was selected phosphate buffer with pH 3.0 and acetonitrile in the ratio of 70:30 (v/v). The peak shape was good at wave-length of $238 \mathrm{~nm}$ with flow rate of $1 \mathrm{~mL} / \mathrm{min}$. Clopidogrel also shows significant UV absorbance at wavelength of $238 \mathrm{~nm}$. Hence, this wavelength has been chosen for detection in analysis of Clopidogrel. The retention of Clopidogrel was found in 4.752 min. (Fig. 2).

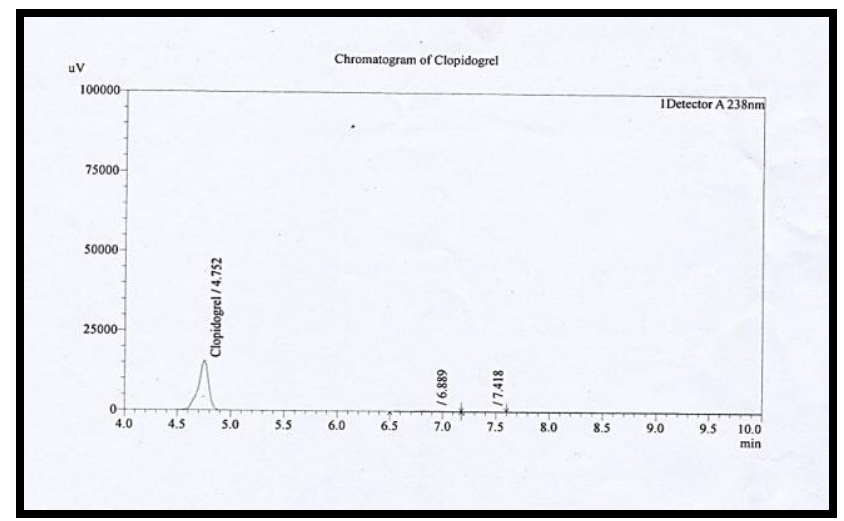

Fig. 2. HPLC chromatogram of Clopidogre.

A linear relationship was obtained between the concentrations of Clopidogrel in the range of $10-60 \mu \mathrm{g} / \mathrm{mL}$ and the respective ratio of peak areas with a correlation coefficient $\left(r^{2}\right)$ of 0.997 , indicating good linearity with representative linear equation of $\mathrm{y}=$ $348.07 x+248610$ (Fig. 3). The limit of detection was found $1.33 \mu \mathrm{g} / \mathrm{mL}$ while the limit of quantification was $3.86 \mu \mathrm{g} / \mathrm{mL}$ (Table 1).

Table 1. Linearity and range test of the developed RP-HPLC method for the determination of Clopidogrel in the pharmaceutical formulation.

\begin{tabular}{llll}
\hline $\begin{array}{l}\text { Conc. of standard } \\
(\mu \mathrm{g} / \mathrm{mL})\end{array}$ & Peak area & Statistical analysis & Pass/Remark \\
\hline 10 & 252295 & & \\
20 & 255676 & & \\
30 & 258895 & Regression correlation & \\
40 & 262256 & coefficient $\left(\mathrm{R}^{2}\right)=0.997$ & \\
50 & 265595 & y-intercept $=248610$ slope of & Passed \\
60 & 270036 & regression line $=348.07$ & \\
Limit of detection (LOD) & & $1.33 \mu \mathrm{g} / \mathrm{mL}$ \\
Limit of quantification (LOQ) & & $3.86 \mu \mathrm{g} / \mathrm{mL}$ \\
\hline
\end{tabular}


The precision of the RP-HPLC method was validated by studying repeatability and intermediate precision. The obtained precision data and recovery studies data are presented in Tables 2-3, respectively. In both cases, \%RSD shows are not more than $2.0 \%$ which indicated good repeatability and intermediate precision as well as the result of recovery study reveal that any small change in the drug concentration in the solution could be accurately determined by the proposed methods.

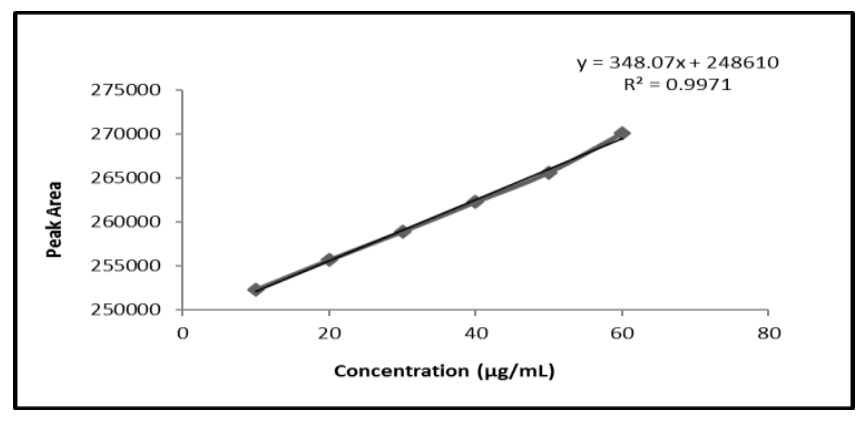

Fig. 3. Calibration curve of Clopidogrel.

Table 2. Result of precision (intraday and interday precision).

\begin{tabular}{ccc}
\hline Parameters & Intraday precision & Interday precision \\
\hline Mean & 75.12 & 75.18 \\
Standard deviation & 1.22 & 1.06 \\
SEM & 0.50 & 0.43 \\
RSD $(\%)$ & 1.62 & 1.41 \\
\hline
\end{tabular}

SEM: Standard error of mean; RSD: Relative standard deviation

Few parameters of the proposed method were deliberately changed to check the robustness of the method. The parameters included variation of flow rate and temperature. The changed flow rate and temperature was $0.8 \mathrm{~mL} / \mathrm{min}$. and $30^{\circ} \mathrm{C}$ in lieu of $1.0 \mathrm{~mL} / \mathrm{min}$. and $25^{\circ} \mathrm{C}$, respectively. The method was found to be robust enough by basis of $\%$ RSD value (Table 4 ).

Table 3. Result of recovery data study of Clopidogrel (Accuracy).

\begin{tabular}{ccccccc}
\hline $\begin{array}{c}\text { Level of } \\
\text { recovery }\end{array}$ & Sample ID & $\begin{array}{c}\text { Theoretical } \\
\text { value }(\mathrm{mg})\end{array}$ & $\begin{array}{c}\text { Actual } \\
\text { value }(\mathrm{mg})\end{array}$ & \% recovery & Mean \pm SD & \% RSD \\
\hline \multirow{3}{*}{$80 \%$} & Spl_01 & 60.91 & 59.95 & 98.42 & & \\
& Spl_02 & 60.91 & 60.80 & 99.82 & $99.41 \pm 0.86$ & 0.86 \\
& Spl_03 & 60.91 & 60.90 & 99.98 & & \\
& Spl_01 & 76.14 & 75.88 & 99.66 & & \\
$100 \%$ & Spl_02 & 76.14 & 76.00 & 99.82 & $99.82 \pm 0.16$ & 0.16 \\
& Spl_03 & 76.14 & 76.12 & 99.97 & & \\
& Spl_01 & 91.37 & 90.11 & 98.62 & & \\
$120 \%$ & Spl_02 & 91.37 & 91.55 & 100.20 & $99.47 \pm 0.80$ & 0.80 \\
& Spl_03 & 91.37 & 91.00 & 99.60 & & \\
\hline
\end{tabular}


Table 4. Robustness data of Clopidogrel.

\begin{tabular}{cccccc}
\hline Injection No. & Peak area & Assay $(\mathrm{mg})$ & Mean & SD & \% RSD \\
\hline 1 & 241394 & 71.49 & & & \\
2 & 245606 & 72.74 & & & \\
3 & 249402 & 73.86 & 73.07 & 0.91 & 1.25 \\
4 & 249513 & 73.01 & & & \\
5 & 247606 & 73.33 & & & \\
6 & 249795 & 74.01 & & & \\
\hline
\end{tabular}

The validated newly method was successfully applied for the analysis of Clopidogrel in commercially available in pharmaceutical dosage forms (tablets). The potency of marketed formulation was determined by this validated method and the results are presented in Table 5. Percentage estimation of drug content from tablet dosage form by this method was $99.57 \%$ with $\%$ RSD value of 0.45 . This value indicates the suitability of this method for routine analysis of Clopidogrel in tablet dosage form.

Table 5. Potency determination of marketed formulation of Clopidogrel.

\begin{tabular}{ccccccc}
\hline Dosage form & SN & Sample code & $\begin{array}{c}\text { Label claim } \\
(\mathrm{mg})\end{array}$ & $\begin{array}{c}\text { Amount found } \\
(\mathrm{mg})\end{array}$ & $\begin{array}{c}\text { Potency } \\
(\%)\end{array}$ & Mean \pm SD \\
\hline \multirow{5}{*}{ Tablet } & 1 & CLO - & 75 & 74.35 & 99.13 & \\
& 2 & CLO - & 75 & 73.90 & 99.53 & \\
& 3 & CLO -3 & 75 & 74.79 & 99.72 & $99.57 \pm 0.45$ \\
& 4 & CLO -4 & 75 & 74.89 & 99.85 & \\
\hline
\end{tabular}

\section{Conclusion}

The outcomes of the present study revealed that the RP-HPLC method developed for quantitative determination of Clopidogrel is precise, accurate and selective. The proposed method is completely validated and satisfactory results and is obtained for all the method validation data tested. Therefore, this method can be used for routine analysis and qualitycontrol assays of Clopidogrel in tablet dosage form.

\section{Acknowledgment}

The authors would like to acknowledge Head of the Department of Pharmacy, Noakhali Science and Technology University, Bangladesh, for providing with laboratory facility and moral support to carry out this research.

\section{References}

1. A. Mounika and N. Sriram, Int. J. Pharm. Ana. Res. 1(1), 1 (2012).

2. N. K. Sahoo, M. Sahu, P. S. Rao, J. N. Indira, S. N. Rani, and G. K. Ghosh, J. Taibah Uni. Sci. 8, 331 (2014).

3. S. J. Rajpur, R. K. George, and B. D. Ruikar, Ind. J. Pharm. Sci. 70, 450 (2008). http://dx.doi.org/10.4103/0250-474X.44592

4. P. B. Chaudhari, P. D. Pawar, and K. P. Narkhede, Int. J. Res. Ayurveda Pharm. 1, 418 (2010). 
5. D. Antic, S. Filpic, and D. Aababa, Acta Chromatogr. 18, 199 (2007).

6. A. Himani, K. Neeraj, A. R Paradkar, and K. R. Mahadik, J. Pharm. Biomed. Anal. 61, 581 (2003).

7. N. P. Gosavi, M. U. Bhajane, and V. V.Patil, Res. J. Pharm. Biol. Chem. Sci. 3, 1065 (2012).

8. M. A. Al-Khayat, S. Haidar, and H. Mando, Int. J. pharm. Sci. Rev. Res. 14, 1 (2012).

9. A. Mounika and N. Sriram, Int. J. Pharm. Anal. Res. 1, 1 (2012).

10. S. S. Panda, Int. J. Pharmatech. Res. 2, 269 (2010).

11. A. Mitakos and I. Panderi, J. Pharm. Biomed. Anal. 28, 431 (2002). http://dx.doi.org/10.1016/S0731-7085(01)00620-3

12. S. Dermis and E. Aydogan, Pharmazie. 65, 175 (2010).

13. ICH, Harmonised Tripartite Guideline, Validation of analytical procedures: Text and Methodology - International Conf. on Harmonization (Q2 (R1), Geneva, 2005).

14. ICH, Harmonised Tripartitle Guideline, Stability Testing of New Drug Substances and Products (Q1A (R1), USA, 2003) pp. 1-18.

15. S. Banik, P. Karmakar, and M. A. H Miah, Bangladesh Pharm. J. 18(2), 163 (2015). 